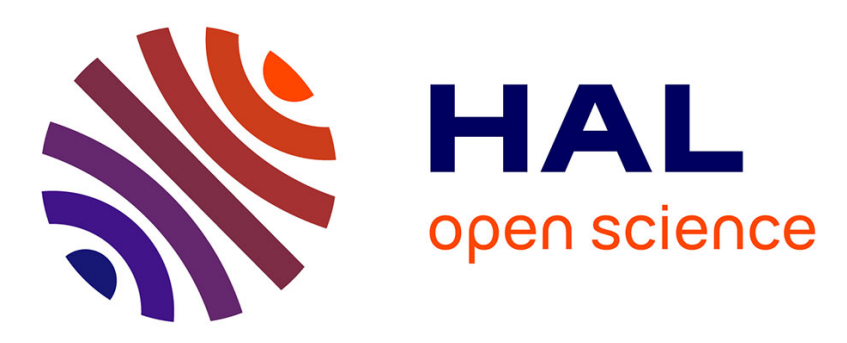

\title{
Role of Ligaments in the Knee Joint Kinematic Behavior: Development and Validation of a Finite Element Model
}

F. Germain, Pierre-Yves Rohan, G. Rochcongar, Philippe Rouch, P. Thoreux, Hélène Pillet, Wafa Skalli

\section{To cite this version:}

F. Germain, Pierre-Yves Rohan, G. Rochcongar, Philippe Rouch, P. Thoreux, et al.. Role of Ligaments in the Knee Joint Kinematic Behavior: Development and Validation of a Finite Element Model. Computational Biomechanics for Medicine, Springer International Publishing, pp.15-26, 2016, 9783319283296. hal-02285091

\section{HAL Id: hal-02285091 https://hal.science/hal-02285091}

Submitted on 15 Oct 2019

HAL is a multi-disciplinary open access archive for the deposit and dissemination of scientific research documents, whether they are published or not. The documents may come from teaching and research institutions in France or abroad, or from public or private research centers.
L'archive ouverte pluridisciplinaire HAL, est destinée au dépôt et à la diffusion de documents scientifiques de niveau recherche, publiés ou non, émanant des établissements d'enseignement et de recherche français ou étrangers, des laboratoires publics ou privés. 


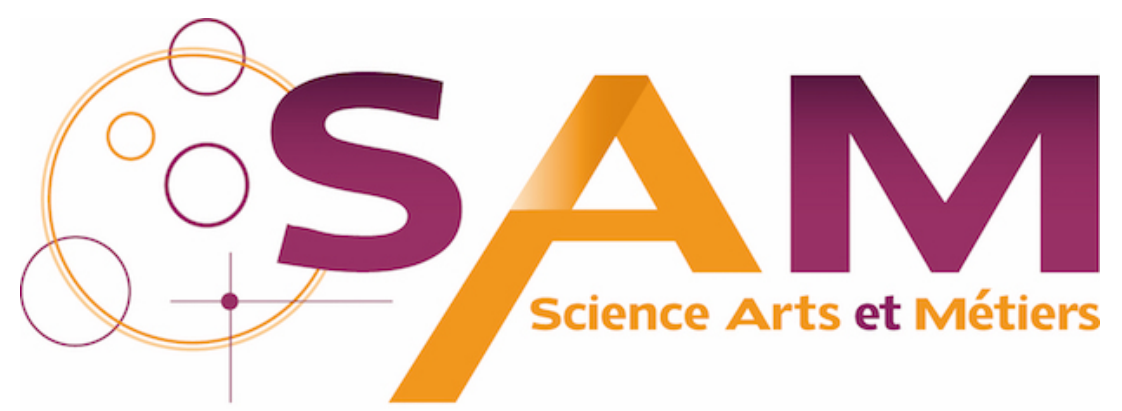

Archive Ouverte - Open Repository

\section{Science Arts \& Métiers (SAM)}

is an open access repository that collects the work of Arts et Métiers ParisTech researchers and makes it freely available over the web where possible.

This is an author-deposited version published in: https://sam.ensam.eu Handle ID: .http://hdl.handle.net/10985/16696

\section{To cite this version :}

F. GERMAIN, Pierre-Yves ROHAN, G. ROCHCONGAR, Philippe ROUCH, P. THOREUX, Hélène PILLET, Wafa SKALLI - Role of Ligaments in the Knee Joint Kinematic Behavior: Development and Validation of a Finite Element Model - 2016 


\title{
Chapter 2 \\ Role of Ligaments in the Knee Joint Kinematic Behavior: Development and Validation of a Finite Element Model
}

\author{
F. Germain, P.Y. Rohan, G. Rochcongar, P. Rouch, P. Thoreux, \\ H. Pillet, and W. Skalli
}

\subsection{Introduction}

The management of knee instability is a complex problem in orthopedic surgery. It usually involves the tear or the rupture of a cruciate or collateral ligament of the articulation and, in many cases, necessitates surgical operation and ligament reconstructions. The rupture of the ACL, in particular, is one of the most frequently occurring ligament injuries affecting about one person in 3000 every year and this trend has been constantly increasing with the rise of participation in sports in the general population [1]. Knee ligamentoplasty has become an issue of high clinical interest.

The current standard of care is based on ligament reconstruction by autografts from tendon tissues, allograft, or ligament substitutes. The assessment, however, of the long-term performance of the surgery is complicated by the complex interaction between the graft parameters (pretensioning, fixation method, etc.), knee anatomy, and the mechanical interaction between the graft and the passive anatomical structures. To this day, no diagnostic tool is available in clinics to quantitatively evaluate and predict the impact of surgery on knee kinematics. This highlights the need for the development of tools to investigate the contribution on knee joint mobility of the ligaments in the normal knee and to establish proper treatment strategies.

In that respect, many studies have been performed both in vitro [2-5] and in vivo [6-9] to study knee kinematics, some of them focusing on influence of the main knee ligaments $[10,11]$. The results varied greatly across studies highlighting the high inter-individual variability.

\footnotetext{
F. Germain $\bullet$ P.Y. Rohan $(\bowtie) \bullet$ G. Rochcongar $\bullet$ P. Rouch $\bullet$ P. Thoreux $\bullet$ H. Pillet $\bullet$ W. Skalli LBM/Institut de Biomécanique Humaine Georges Charpak, Arts et Metiers ParisTech, 151 bvd de l'Hôpital, 75013 Paris, France e-mail: pierreyves.rohan@live.fr
} 
Several finite element (FE) knee models have also been developed in an effort to comprehensively investigate various aspects of knee mechanics including contact pressure under various loads [12-18], ligament stress [19-21], or the dynamic behavior [14, 22, 23]. A few of them studied knee kinematics [12, 14, 24, 25]. The high numerical costs associated with the computation of the biomechanical response of the knee joint and the full validation of these models against tibio-femoral and tibio-patellar kinematic data, however, are still a main issue [14], particularly for patellofemoral motion because of uncertainty in patellar tracking.

A new experimental setup was recently developed combining 3D reconstruction imaging with the use of a motion capture system for accurate analysis of knee joint kinematics at our laboratory [2]. The aim of the present study was to develop an FE model capable of reproducing the kinematic of the knee in flexion/extension and, building upon the work of Azmy, to validate it with in vitro experimentations for investigating the impact of ligament properties on the knee kinematics.

\subsection{Materials and Methods}

\subsubsection{Finite Element Model}

Geometry The model developed in this study is an adaptation of the one proposed by [26]. The 3D geometry of the bony structures was acquired using a sensor pen (Fastrak system, Polhemus, Olchester, USA), and was carried out on a left 63-yearold female lower limb.

Elements and Meshing The FE mesh, represented in Fig. 2.1, consists of the distal and proximal part of the femur and tibia, respectively, the patella, the quadriceps tendon, the cartilage, and knee ligaments. Bones and cartilage were meshed with low-order (four-nodes) shell elements, the quadriceps tendon with loworder membrane elements, and the ligaments with tension-only cables.

The different ligament bundles were represented: (1) two bundles for each cruciate ligament (antéro-médial (AM) and postéro-lateral (PL) bundles for the Anterior cruciate ligament (ACL); antéro-latéral (AL) and postéro-médial (PM) bundles for the Posterior cruciate ligament (PCL)), (2) four bundles for the Collateral Ligaments (CoL) (three for the medial collateral ligament (MCL) and one for the lateral collateral ligament (LCL)), (3) five bundles for the patellar ligament, and (4) seven for the articular capsule.

Material Properties The material properties used for each component are summarized in Tables 2.1 and 2.2. Bones and cartilage were defined as linear elastic isotropic material in accordance with the literature [27, 28]. The regions covered with cartilage were modeled as a homogeneous bone cartilage material, with average properties. A thin strip of elements between the bones and cartilage 
Fig. 2.1 FE knee model. (a) Isometric view (front); (b) isomeric view (back). The femur and tibia were limited to their respective distal and proximal parts
Table 2.1 Material properties of bones and cartilage a

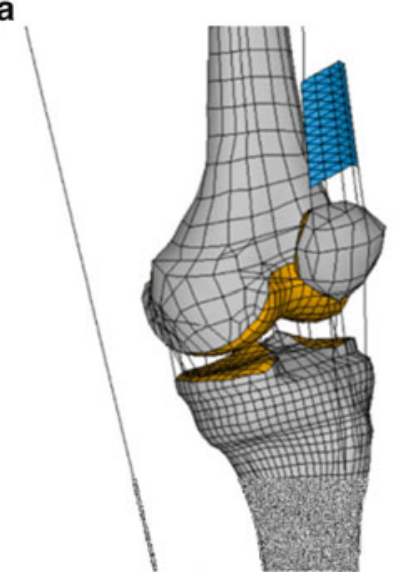

b

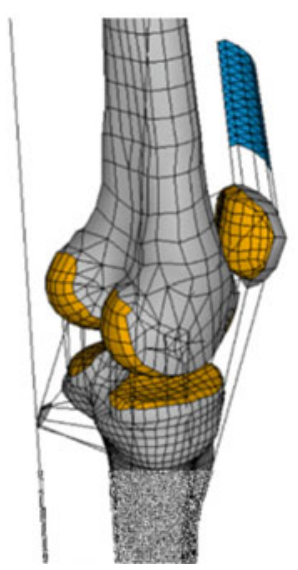

\begin{tabular}{l|r|l}
\hline & $E(\mathrm{MPa})$ & $v$ \\
\hline Cortical bone and patella & \multicolumn{1}{|l}{12,000} & 0.3 \\
\hline Bone/cartilage inter & 2000 & 0.4 \\
\hline Bone/cartilage & 250 & 0.4 \\
\hline Tendon & 90 & 0.4 \\
\hline
\end{tabular}

Table 2.2 Material properties of the different ligament bundles

\begin{tabular}{l|l|c}
\hline & $K(\mathrm{~N} / \mathrm{mm})$ & Initial strain $(\%)$ \\
\hline Anterior cruciate ligament (ACL) & 75 & 5 \\
\hline Posterior cruciate ligament (PCL) & 75 & -3 \\
\hline MCL & 70 & 0 \\
\hline LCL & 20 & 0
\end{tabular}

regions were also defined with intermediate properties in order to avoid important mechanical discontinuity.

The stiffness of the different ligament bundles was chosen in accordance with the experimental data reported in literature [29-34]. Negative initial strain for PCL indicates a slack condition.

Contact Four frictionless surface-to-surface contact zones were created: femur (lateral)/tibia (lateral), femur (medial)/tibia (medial), femur/patella, and femur/quadriceps tendon. The interactions between the ligaments and bones represented in the model are not modeled in the present study.

Boundary Conditions The experimental boundary conditions [2] were imposed: the femur was fixed, the rope and pulley system was represented as two cables driven by temperature, and a set of 130 consecutive displacements of $0.5 \mathrm{~mm}$ were applied to the quadriceps tendon. This allowed to generate forces in the cables that were always directed toward the center of the femoral head. 
Fig. 2.2 Validated experimental setup used for testing the lower limbs in flexion/extension. (a) Whole setup with the rope and pulley system for applying the flexion. (b) Position of the tripods
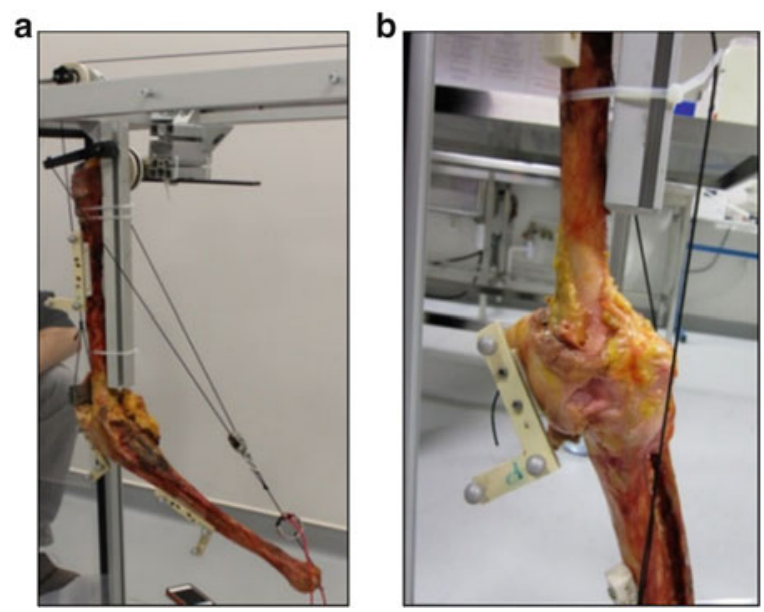

Solution The large deformation static response was computed using an implicit solver in ANSYS.

\subsubsection{Model Evaluation}

Sample Preparation Twenty-three fresh frozen lower limbs were used. The subjects from whom they were harvested were 47-97 years old. Absence of osteoarthritis and ligament laxity was checked. Specimens were disarticulated at the head of the femur and at the distal epiphysis of the tibia. All the soft tissues were removed except for the articular capsule of the knee, the quadriceps tendon, the CoL of the knee (medial and lateral), the patellar ligament, and the proximal and distal ligaments between the tibia and the fibula. The samples were frozen at $-20{ }^{\circ} \mathrm{C}$ then thawed at room temperature $12 \mathrm{~h}$ before experimentation.

Test Bench The validated test bench, represented in Fig. 2.2, was adapted from [2]. The femur was fixed and the tibia was free. Tension was applied to the quadriceps tendon using a weight of $9.8 \mathrm{~N}$. A motor was connected to the tibial pilon by a rope and was used to perform the flexion movement. A progressive displacement was applied at the centroid of the malleolus and directed toward the center of the femoral head.

Movement Tracking Tripods were fixed on the femoral diaphysis, the proximal epiphysis, and the patella. During the cycles of flexion/extension, the position of the bony segments was tracked with a Polaris optoelectronic system (NDI, Waterloo, Ontario, Canada).

Anatomical Frames The position of the tripods in their respective anatomical frames was calculated from $3 \mathrm{D}$ reconstruction made with the $\mathrm{EOS}^{\circledR}$ bi-planar 
Table 2.3 Stiffness and initial strain chosen for the sensitivity cases on the ACL

\begin{tabular}{l|l|c|l|l|l|c}
\hline & \multicolumn{3}{|l|}{$K(\mathrm{~N} / \mathrm{mm})$} & \multicolumn{3}{l}{ Initial strain (\%) } \\
\cline { 2 - 7 } & Min & Mean & Max & Min (\%) & Mean (\%) & Max (\%) \\
\hline ACL bundle & 40 & 75 & 150 & 0 & 3 & 6 \\
\hline PCL bundle & 40 & 75 & 150 & 3 & 0 & -4 \\
\hline MCL & 70 & 100 & 120 & 0 & 2 & 4 \\
\hline LCL & 20 & 60 & 120 & 0 & 2 & 4 \\
\hline
\end{tabular}

X-ray system. The experimental setup was put in the EOS cabin and bi-planar radiographies were acquired. A geometric reconstruction of the bony structures was performed and used for the calculation of the anatomical frames.

Movement Analysis The variation of relative position tibia/femur and patella/ femur was extrapolated using a MATLAB ${ }^{\circledast}$ routine. The rotations were calculated on mobile axis, with the following sequence (center of rotations): $z y^{\prime} x^{\prime \prime}$ ( $y^{\prime}$ denoting the mobile $y$ axis after the first rotation about $z$, and $x^{\prime \prime}$ denoting the mobile $x$ axis after the first two rotations).

\subsubsection{Sensitivity Analysis}

A sensitivity analysis was conducted to investigate the impact of ligaments on the knee kinematics. The stiffness and initial strain of one or several bundles of ligament were modified and the impact in the tibia position was computed. Ten cases were considered. These are summarized in Table 2.3. Stiffness values were defined based on data reported in the literature [29-34]. Initial strain values were chosen so that strains remained below the physiological limit whilst being sufficiently different from one another.

\subsection{Results}

\subsubsection{Experimental/Numerical Comparison}

Tibial Kinematics Both the experimental corridor of the tibial kinematics with respect to the femur and the numerical results computed with our model are shown in Fig. 2.3. Our results show that the angular position of the tibia of the finite element model is in the physiological corridor. During flexion, the tibial movement predicted by the FE model does an internal rotation (Fig. 2.3) of up to $-11.9^{\circ}$ at $70^{\circ}$ flexion (while the in vitro experiment is in the corridor $\left[-18.3^{\circ} ;-7.2^{\circ}\right]$ ). Our results also 

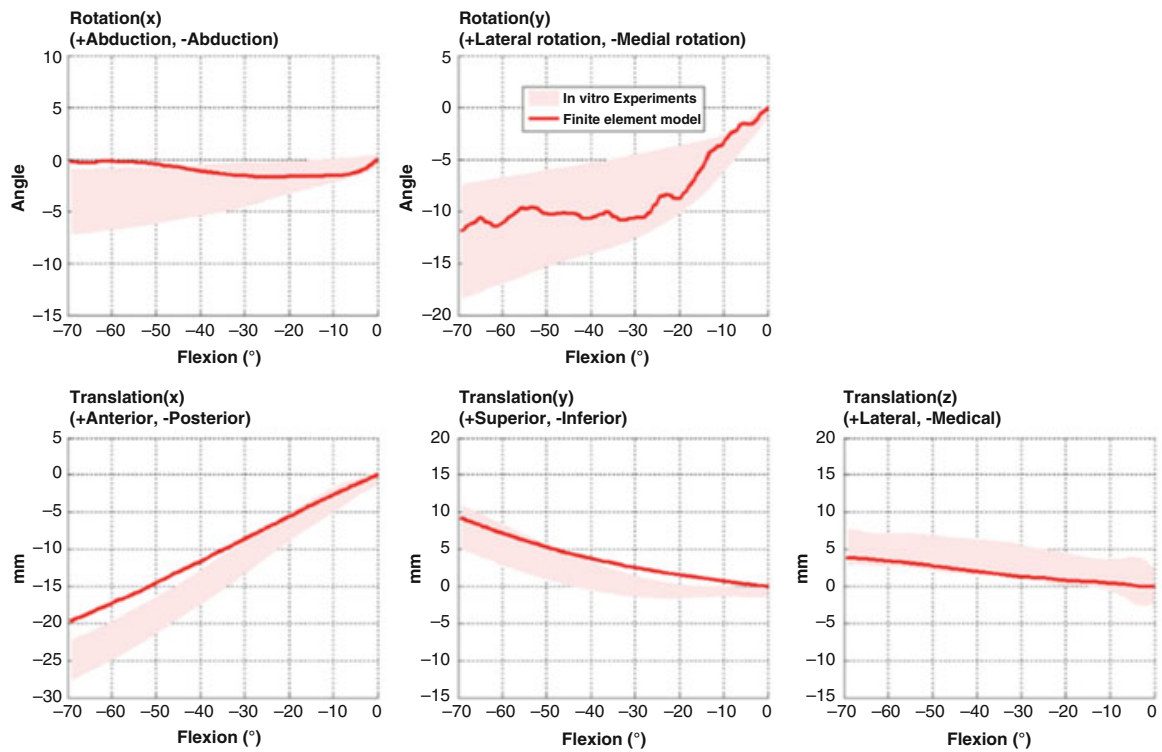

Fig. 2.3 Tibial kinematics (with respect to the femur) during the range of motion

show a slight adduction: down to $-1.71^{\circ}$ at $20^{\circ}$ flexion and then back to $-0.26^{\circ}$ at $70^{\circ}$ of flexion $\left(\left[-7.1^{\circ} ;-0.9^{\circ}\right]\right.$ for the in vitro experiments).

Patellar Kinematics Both the experimental corridor of the patellar kinematics with respect to the femur and the numerical results computed with our model are shown in Fig. 2.4. The results obtained using the finite element model are within the physiological corridor of the $x, y$, and $z$ rotations and the $z$ translation.

\subsubsection{Influence on the Femoro-Tibial Kinematics}

The influence of the ligament parameters on the femoro-tibial kinematics is reported in Table 2.4, mean value and standard deviation of tibia position at $60^{\circ}$ flexion for each case. Concerning the Rx rotation (abduction/adduction), the ligament that had the most influence was the ACL, followed by the LLE, the PCL, and the MCL holding a smaller influence $\left(\mathrm{SD}<0.35^{\circ}\right)$. The Ry rotation is mainly influenced by the PCL and the LCL, the PL bundle of ACL holding a smaller influence $\left(\mathrm{SD}<1.01^{\circ}\right)$. The Tx translation was influenced mainly by the ACL and the PCL when both bundles are modified at the same time. The Ty translation was influenced mainly by the AM bundle of the MCL and the cruciate ligaments when the four ligaments are modified at the same time. The Tz translation is influenced mainly by the ACL, the AL bundle of the PCL, and the LCL. 

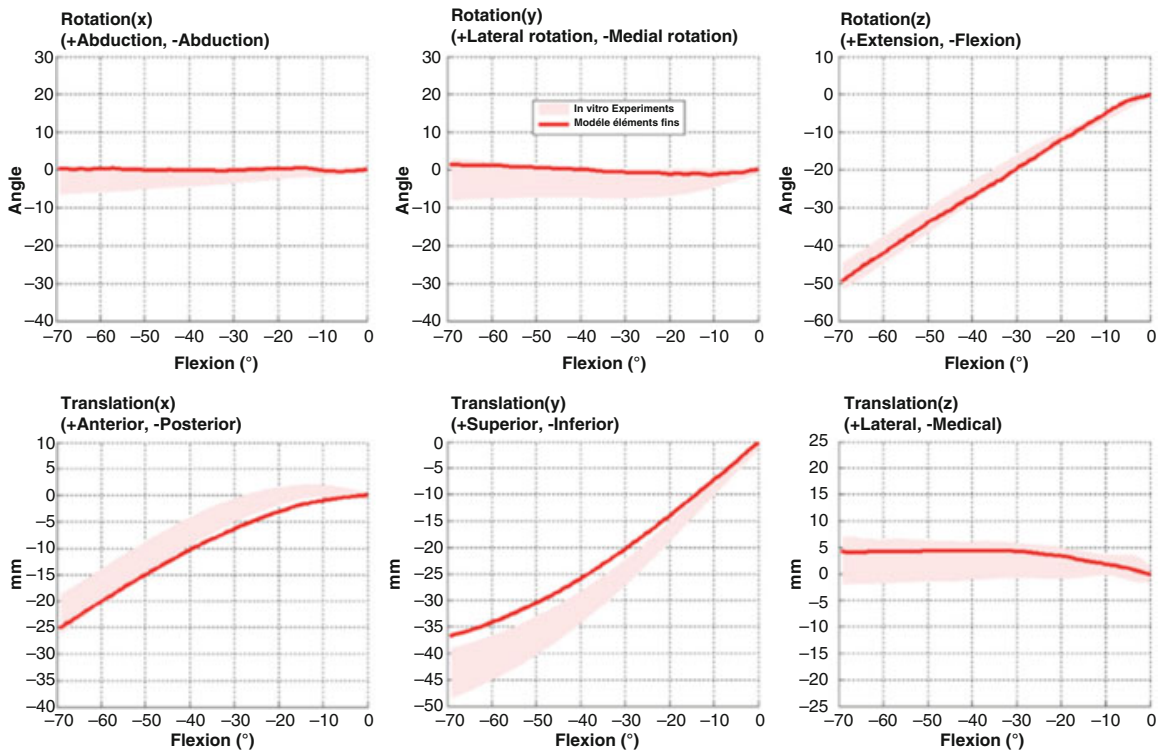

Fig. 2.4 Patellar kinematics (with respect to the femur)

Table 2.4 Mean value and standard deviation of tibia position at $60^{\circ}$ flexion for each sensitivity case (the ligament column shows which ligament was modified)

\begin{tabular}{|c|c|c|c|c|c|c|}
\hline \multicolumn{2}{|l|}{ Ligament } & $\operatorname{Rx}\left({ }^{\circ}\right)$ & $\operatorname{Ry}\left({ }^{\circ}\right)$ & Tx (mm) & Ty $(\mathrm{mm})$ & $\mathrm{Tz}(\mathrm{mm})$ \\
\hline \multirow[t]{2}{*}{ ACL (AM) } & Mean & -1.2 & -13.9 & -17.3 & 5.9 & 3.0 \\
\hline & SD & 1.0 & 0.5 & 0.5 & 0.5 & 0.2 \\
\hline \multirow[t]{2}{*}{ ACL (PL) } & Mean & -0.5 & -15.5 & -16.8 & 5.0 & 3.0 \\
\hline & SD & 0.6 & 1.0 & 0.9 & 0.2 & 0.2 \\
\hline \multirow[t]{2}{*}{$A C L$ (all) } & Mean & -1.3 & -14.2 & -17.2 & 5.9 & 2.9 \\
\hline & $S D$ & 1.0 & 0.3 & 0.4 & 0.6 & 0.2 \\
\hline \multirow[t]{2}{*}{ PCL (AL) } & Mean & 0.0 & -15.6 & -17.9 & 5.1 & 3.1 \\
\hline & SD & 0.1 & 1.8 & 0.3 & 0.1 & 0.1 \\
\hline \multirow[t]{2}{*}{ PCL (PM) } & Mean & 0.1 & -15.2 & -17.7 & 5.1 & 3.2 \\
\hline & SD & 0.3 & 1.4 & 0.2 & 0.3 & 0.0 \\
\hline \multirow[t]{2}{*}{ PCL (all) } & Mean & 0.3 & -14.8 & -17.2 & 5.0 & 3.2 \\
\hline & $S D$ & 0.3 & 3.0 & 0.8 & 0.4 & 0.1 \\
\hline \multirow[t]{2}{*}{ MCL (all) } & Mean & 0.2 & -14.2 & -17.7 & 5.2 & 3.2 \\
\hline & SD & 0.2 & 0.3 & 0.1 & 0.1 & 0.1 \\
\hline \multirow[t]{2}{*}{ LCL } & Mean & 0.2 & -14.6 & -17.6 & 5.1 & 3.2 \\
\hline & SD & 0.7 & 1.7 & 0.2 & 0.1 & 0.2 \\
\hline \multirow[t]{2}{*}{ CoL (all) } & Mean & 0.2 & -14.3 & -17 & 5.1 & 3.0 \\
\hline & $S D$ & 0.7 & 1.3 & 0.1 & 0.1 & 0.1 \\
\hline
\end{tabular}


Table 2.5 Comparison of the experimental and computational results with literature: kinematics of the femoro-tibial articulation at $60^{\circ}$ flexion

\begin{tabular}{l|l|l|l|l|l|l}
\hline Study & Specimens & $\operatorname{Rx}\left({ }^{\circ}\right)$ & $\operatorname{Ry}\left({ }^{\circ}\right)$ & Tx $(\mathrm{mm})$ & Ty $(\mathrm{mm})$ & $\mathrm{Tz}(\mathrm{mm})$ \\
\hline FE model & - & 0 & -11.5 & -17.2 & 7.5 & 4.9 \\
\hline In vitro exp & 23 & $-3 \pm 3$ & $-12 \pm 5.2$ & $-22.5 \pm 2.5$ & $5.5 \pm 2.5$ & $3.3 \pm 2.7$ \\
\hline$[35]$ & 15 & $-3 \pm 3$ & $-16.5 \pm 5$ & $-16.7 \pm 3.7$ & $7.5 \pm 3$ & $4 \pm 1.5$ \\
\hline$[5]$ & 8 & - & $-11 \pm 4$ & - & - & - \\
\hline$[36]$ & 15 & - & $-17.1 \pm 1.8$ & - & - & - \\
\hline$[3]$ & 13 & - & $-6.5 \pm 3$ & $-14 \pm 5$ & - & - \\
\hline
\end{tabular}

Despite the numerous contact elements in the model, the computation time was below $1 \mathrm{~h}$. Model-predicted response was within the experimental corridors for all translations and rotations of tibia and patella with respect to the femur, except for $\mathrm{a} \pm 2^{\circ}$ max discrepancy in the abduction/adduction rotation of the patella. The different ligament parameters appeared to have little effect on the patellar anterior/posterior and inferior/posterior shifts while the kinematic response of the tibial anterior/posterior shift was more sensitive.

\subsection{Discussion}

Very few FE models reported in the literature feature extensive validation against both tibio-femoral and tibio-patellar kinematic data. These are paramount to comprehensively assess the biomechanical role of the knee joint and to investigate various aspects of knee instability such as knee ligament injuries, ligament replacement, and ACL graft design.

In this contribution, an FE of the knee joint capable of reproducing the kinematics of the knee in flexion/extension for the investigation of the role of ligaments in the joint kinematic behavior was created and validated against the experimental data of 23 cadavers. Special attention was paid to keep the numerical cost as low as possible. Low-order shell elements and cable elements were therefore used to discretize the components of the geometric model.

For both the tibial and patellar kinematics, the results computed with our model are inside or at the limit of the experimental corridors. Both the experimental and computational results obtained for the femoro-tibial and the femoro-patellar kinematics are comparable to the literature. Tables 2.5 and 2.6 summarize and compare the kinematic values reported in this study with the main values reported in the literature.

As for model evaluation, Kiapour et al. [14] presented extensive validation using 16 lower limbs and investigation of several parameters. However, patellofemoral kinematics was not evaluated. 
Table 2.6 Comparison of the experimental and computational results with literature: kinematics of the femoro-patellar articulation at $60^{\circ}$ flexion

\begin{tabular}{l|l|l|l|l|l|l}
\hline Study & Specimens & $\operatorname{Rx}\left({ }^{\circ}\right)$ & $\operatorname{Ry}\left({ }^{\circ}\right)$ & $\mathrm{Tx}(\mathrm{mm})$ & $\mathrm{Ty}(\mathrm{mm})$ & $\mathrm{Tz}(\mathrm{mm})$ \\
\hline FE model & - & 0 & 0.5 & -41.5 & -20 & -34 \\
\hline In vitro exp & 23 & $-3 \pm 3$ & $-3.5 \pm 4.5$ & $-41.5 \pm 3.5$ & $-17 \pm 3$ & $-41 \pm 4$ \\
\hline$[2]$ & 8 & $-3 \pm 3$ & $0.5 \pm 7.5$ & $-38 \pm 4$ & $-14 \pm 4$ & $-40 \pm 8$ \\
\hline$[5]$ & 8 & $1.5 \pm 3$ & $3 \pm 5.5$ & - & - & - \\
\hline$[37]$ & 6 & $1 \pm 5.5$ & $-1 \pm 10$ & - & - & - \\
\hline$[4]$ & 7 & $0 \pm 4$ & $-2 \pm 5$ & - & - & - \\
\hline
\end{tabular}

The sensitivity analysis conducted on the main ligaments of the tibio-femoral articulation highlighted the importance of distinguishing the two bundles of the ACL and the PCL, since they do not impact the femoro-tibial kinematics in the same way: the AM bundle of the ACL exerts more than twice as much influence on Ry and Tx, but less than twice as much on Rx and Ty as compared with the PL bundle. Likewise, modifying both bundles of the PCL significantly increases the influence on Rx, Ry, and Tx, but doesn't have much effect on Ty and Tz.

Two main limitations of our model are the omission of (1) the meniscus, the popliteal tendon, and the popliteo-fibular ligament, in order to keep the computation time as low as possible. This might explain the small experimental-numerical kinematic discrepancies and could be taken into account to improve the realism of the model. The simplification of the ligament insertion and the absence of ligament/ligament contact could also explain the fact that, in the simulation results, the ligament effect remains small. (2) The geometry of the finite element model is not personalized. Yet the geometry has a strong impact on the femoro-tibial and the femoro-patellar kinematics for at least two reasons: it affects the morphology of the contact surface, and it can determine the position of anatomical landmarks from which the boundary conditions are defined (center of the femoral head, center of the malleoli).

Nonetheless, the model appears consistent with in vitro kinematics and the computational cost remains reasonable $(1 \mathrm{~h})$. From a clinical perspective, the developed knee model constitutes a valuable tool for exploring new treatment strategies, such as the development of ACL substitutes for ligament reconstructions where it can be used to test different designs and evaluate the restoration of knee kinematics right after implantation.

\subsection{Conclusions}

An FE of the knee joint capable of reproducing the kinematic of the knee in flexion/extension for the investigation of the role of ligaments in the joint kinematic behavior was created and validated against the experimental data of 23 cadavers. 
Special attention was paid to keep the numerical cost as low as possible. For both the tibial and patellar kinematics, the results computed with our model are inside the experimental corridor. Both the experimental and computational results obtained for the femoro-tibial and the femoro-patellar kinematics are also comparable to data reported in the literature. From a clinical perspective, the developed knee model constitutes a valuable tool for exploring new treatment strategies, such as the development of ACL substitutes for ligament reconstructions where it can be used to test different designs and evaluate the restoration of knee kinematics right after implantation.

\section{References}

1. D.M. Doroski, K.S. Brink, J.S. Temenoff, Techniques for biological characterization of tissueengineered tendon and ligament. Biomaterials 28(2), 187-202 (2007)

2. C. Azmy, S. Guérard, X. Bonnet, F. Gabrielli, W. Skalli, EOS ${ }^{\oplus}$ orthopaedic imaging system to study patellofemoral kinematics: assessment of uncertainty. Orthop. Traumatol. Surg. Res. 96(1), 28-36 (2010)

3. G. Li, S. Zayontz, L.E. DeFrate, E. Most, J.F. Suggs, H.E. Rubash, Kinematics of the knee at high flexion angles: an in vitro investigation. J. Orthop. Res. 22(1), 90-95 (2004)

4. A. Lorenz, O. Müller, P. Kohler, M. Wünschel, N. Wülker, U.G. Leichtle, The influence of asymmetric quadriceps loading on patellar tracking - an in vitro study. Knee 19(6), 818-22 (2012)

5. R. Nagamine, L.A. Whiteside, T. Otani, S.E. White, D.S. McCarthy, Effect of medial displacement of the tibial tubercle on patellar position after rotational malposition of the femoral component in total knee arthroplasty. J. Arthroplasty 11(1), 104-110 (1996)

6. M.S. Andersen, D.L. Benoit, M. Damsgaard, D.K. Ramsey, J. Rasmussen, Do kinematic models reduce the effects of soft tissue artefacts in skin marker-based motion analysis? An in vivo study of knee kinematics. J. Biomech. 43(2), 268-273 (2010)

7. L. Lucchetti, A. Cappozzo, A. Cappello, U.D. Croce, Skin movement artefact assessment and compensation in the estimation of knee-joint kinematics. J. Biomech. 31(11), 977-984 (1998)

8. C.B. Ma, K. Lee, M.A. Schrumpf, S. Majumdar, Analysis of three-dimensional in vivo knee kinematics using dynamic magnetic resonance imaging. Oper. Tech. Orthop. 15(1), 57-63 (2005)

9. K. Suzuki, N. Hara, S. Mikami, T. Tomita, K. Iwamoto, T. Yamazaki et al., In vivo kinematic analysis of posterior-stabilized total knee arthroplasty for the valgus knee operated by the gapbalancing technique. Knee 21(6), 1124-1128 (2014)

10. L. Blankevoort, R. Huiskes, A. De Lange, Recruitment of knee joint ligaments. J. Biomech. Eng. 113(1), 94-103 (1991)

11. B.T. Feeley, M.S. Muller, A.A. Allen, C.C. Granchi, A.D. Pearle, Isometry of medial collateral ligament reconstruction. Knee Surg. Sports Traumatol. Arthrosc. 17(9), 1078-1082 (2009)

12. M. Adouni, A. Shirazi-Adl, R. Shirazi, Computational biodynamics of human knee joint in gait: from muscle forces to cartilage stresses. J. Biomech. 45(12), 2149-2156 (2012)

13. Z. Hao, D. Jin, Y. Zhang, J. Zhang, A Finite Element 3D Model of In Vivo Human Knee Joint Based on MRI for the Tibiofemoral Joint Contact Analysis, ed. by VG Duffy. Digital Human Modeling [Internet] (Springer, Berlin, 2007), pp. 616-22 [cited 2015 June 4]. http:// link.springer.com/chapter/10.1007/978-3-540-73321-8_70

14. A. Kiapour, A.M. Kiapour, V. Kaul, C.E. Quatman, S.C. Wordeman, T.E. Hewett et al., Finite element model of the knee for investigation of injury mechanisms: development and validation. J. Biomech. Eng. 136(1), 011002 (2013) 
15. X. Liu, M. Zhang, Redistribution of knee stress using laterally wedged insole intervention: finite element analysis of knee-ankle-foot complex. Clin. Biomech. 28(1), 61-67 (2013)

16. G. Papaioannou, G. Nianios, C. Mitrogiannis, D. Fyhrie, S. Tashman, K.H. Yang, Patientspecific knee joint finite element model validation with high-accuracy kinematics from biplane dynamic Roentgen stereogrammetric analysis. J. Biomech. 41(12), 2633-2638 (2008)

17. C. Rao, C.K. Fitzpatrick, P.J. Rullkoetter, L.P. Maletsky, R.H. Kim, P.J. Laz, A statistical finite element model of the knee accounting for shape and alignment variability. Med. Eng. Phys. 35(10), 1450-1456 (2013)

18. Y. Wang, Y. Fan, M. Zhang, Comparison of stress on knee cartilage during kneeling and standing using finite element models. Med. Eng. Phys. 36(4), 439-447 (2014)

19. G. Limbert, M. Taylor, J. Middleton, Three-dimensional finite element modelling of the human ACL: simulation of passive knee flexion with a stressed and stress-free ACL. J. Biomech. 37(11), 1723-1731 (2004)

20. N.A. Ramaniraka, P. Saunier, O. Siegrist, D.P. Pioletti, Biomechanical evaluation of intraarticular and extra-articular procedures in anterior cruciate ligament reconstruction: a finite element analysis. Clin. Biomech. 22(3), 336-343 (2007)

21. F. Xie, L. Yang, L. Guo, Z. Wang, G. Dai, A study on construction three-dimensional nonlinear finite element model and stress distribution analysis of anterior cruciate ligament. J. Biomech. Eng. 131(12), 121007 (2009)

22. E.M. Abdel-Rahman, M.S. Hefzy, Three-dimensional dynamic behaviour of the human knee joint under impact loading. Med. Eng. Phys. 20(4), 276-290 (1998)

23. P. Beillas, G. Papaioannou, S. Tashman, K.H. Yang, A new method to investigate in vivo knee behavior using a finite element model of the lower limb. J. Biomech. 37(7), 1019-1030 (2004)

24. M.A. Baldwin, C.W. Clary, C.K. Fitzpatrick, J.S. Deacy, L.P. Maletsky, P.J. Rullkoetter, Dynamic finite element knee simulation for evaluation of knee replacement mechanics. J. Biomech. 45(3), 474-483 (2012)

25. W. Mesfar, A. Shirazi-Adl, Biomechanics of the knee joint in flexion under various quadriceps forces. Knee 12(6), 424-434 (2005)

26. J. Noailles, Modelisation Elements Finis De L'articulation Du Genou [Internet] (ENSAM, Paris, 1999) [cited 2015 Jun 5]. http://www.theses.fr/1999ENAM0039

27. K. Choi, J.L. Kuhn, M.J. Ciarelli, S.A. Goldstein, The elastic moduli of human subchondral, trabecular, and cortical bone tissue and the size-dependency of cortical bone modulus. J. Biomech. 23(11), 1103-1113 (1990)

28. R.Y. Hori, L.F. Mockros, Indentation tests of human articular cartilage. J. Biomech. 9(4), 259268 (1976)

29. A.A. Amis, A.M.J. Bull, C.M. Gupte, I. Hijazi, A. Race, J.R. Robinson, Biomechanics of the PCL and related structures: posterolateral, posteromedial and meniscofemoral ligaments. Knee Surg. Sports Traumatol. Arthrosc. 11(5), 271-281 (2003)

30. D.L. Butler, M.D. Kay, D.C. Stouffer, Comparison of material properties in fascicle-bone units from human patellar tendon and knee ligaments. J. Biomech. 19(6), 425-432 (1986)

31. N. Chandrashekar, H. Mansouri, J. Slauterbeck, J. Hashemi, Sex-based differences in the tensile properties of the human anterior cruciate ligament. J. Biomech. 39(16), 2943-2950 (2006)

32. A. Race, A.A. Amis, The mechanical properties of the two bundles of the human posterior cruciate ligament. J. Biomech. 27(1), 13-24 (1994)

33. J.R. Robinson, A.M. Bull, A.A. Amis, Structural properties of the medial collateral ligament complex of the human knee. J. Biomech. 38(5), 1067-1074 (2005)

34. T. Sugita, A.A. Amis, Anatomic and biomechanical study of the lateral collateral and popliteofibular ligaments. Am. J. Sports Med. 29(4), 466-472 (2001)

35. D.R. Wilson, J.D. Feikes, A.B. Zavatsky, J.J. O'Connor, The components of passive knee movement are coupled to flexion angle. J. Biomech. 33(4), 465-473 (2000) 
36. T. Zantop, T. Schumacher, N. Diermann, S. Schanz, M.J. Raschke, W. Petersen, Anterolateral rotational knee instability: role of posterolateral structures. Winner of the AGA-DonJoy Award 2006. Arch. Orthop. Trauma Surg. 127(9), 743-752 (2007)

37. R. Philippot, J. Chouteau, R. Testa, B. Moyen, In vitro analysis of patellar kinematics: validation of an opto-electronic cinematic analysis protocol. Knee Surg. Sports Traumatol. Arthrosc. 18(2), 161-166 (2010) 